\title{
BEHAVIORISM IN FOREIGN LANGUAGE TEACHING METHODOLOGY
}

\author{
Asep Budiman \\ The Faculty of Teacher Training and Education, \\ Sebelas Maret University, \\ asepbudiman@student.uns.ac.id
}

\begin{abstract}
This paper aims at exploring in details about one of the left language learning theoriesnamely Behaviorism. Behaviorism, as how it is today, is gradually left behind since there are many new theories of language learning. Regarding this issue, it is very important to ensure that actually Behaviorism is still useful in certain teaching and learning activities in the classroom. This review investigates behaviorism methodology having advantages in learning a language in the classroom. This review also observes the critics of behaviorism and its weaknesses in a learning environment. This inquiry concentrates on the view point of B.F. Skinner, one of the most outspoken behaviorism psychologist and his experimentations about animals. The notion of antimentalism of behaviorism also is discussed in the process.
\end{abstract}

Keywords: Behaviorism Theory, Foreign Language, Teaching Methodology

\section{INTRODUCTION}

Learning is an individual activity that conducts studies, work processes internal factors. According to Skinner (1976), learning is a process of adjustment to adaptation through has simulation and accommodation between the basic units of cognition stimulation with someone. In the view of psychology behavior is miscue to the interaction between stimulus and response. A personis considered to havelearnedsomethingif shecanshow changes inbehavior. According to this theory, the importance of learning is a form of stimulus input and output in the form of the response. 
If the terms of a concept or theory, theory of foreign language learning has long been discussed to find the best way how foreign language can be taught effectively. In this case, theory becomes crucial since it helps the teacher to perceive the phenomenon in the world of learning. It contains of framework of concepts, and principles as well (Lodico, Spaulding, Voegtle, 2006). Speaking of theory in language learning, there are four major and familiar theories of language acquisition and language learning namely behaviorism, cognitivism, humanism, and constructivism (Fauziati, 2016). Based on its development, behaviorism is the first theory developed by some key figures such as Pavlov, Watson, Thorndike, and Skinner. Put simply, behaviorists' view on learning is that it focuses on how learners' behavior is shaped through stimulus and response. They also view that behavior is observable.

Behaviorism theory is certainly different from other theories. This can be seen in everyday classroom learning. There are different assumptions or views that appear on behaviorism theory (Leahey, 2000). Behaviorism theory views that learning is changing the behavior of students, from being able to produce oral or written product, and the task of the teacher is to control the stimulus and the learning environment in order to change the desired destination approaching, gift giver sand teachers of students who have been able to show significant changes while punishment given to students who are notable to show the change of meaning.

It is necessary to holddiscussionof thetheoryof behaviorism. This paper will briefly examine an overview of behaviorism theory, how behaviorism theory is applied to a particular method of foreign language teaching methodology, and to an approach of teaching writing named teaching writing as product. Hopefullythe discussion will result in minimizingfalse assumptionsaboutthe theory ofbehaviorism understanding of why teachers choose a particular method or technique of teaching for particular learners with particular learning objectives. 


\section{THEORITICAL FRAMEWORK}

\section{Understanding Behaviorism Theory}

Behaviorism learning theory oriented "results that can be measured, observed, analyzed, and tested objectively". Repetition and training used so that the desired behavior can become a habit. The expected result of the application of the theory of behaviorism is the formation of a desired behavior. Desired behavior gets positive reinforcement and behavior that are less fit awarded negative. Evaluation or assessment is based on observed behavior. In this theory, a lot of teachers do not lecture, but brief instructions are followed example, either by themselves or through stimulation (Skinner, 1976).

Behaviorism Learning Theory is a theory of learning that emphasizes human behavior as a result of the interaction between stimulus and response. Behaviorism theory is a theory proposed by Gage and Berliner. This theory later developed into the flow of learning psychology that influence the development of education and learning theory known as behaviorism flow. This emphasis on the formation of the flow behavior appears to be a result of learning.

Behaviorism theory with stimulus-response relationship model, seated person as an individual passive learning (Alissa, 2003). Specific behavioral responses analyzed by using training methods or habituation alone. The emergence of behaviors will be stronger when given reinforcement and will disappear when sentenced. A person is considered to have learned something if he can show changes in behavior. According to this theory the important learning is in the form of inputs and outputs in the form of stimulus response.

Stimulus is all that is given by the teacher to the learner, while the response in the form of student reactions or responses to the stimulus given by the teacher. Processes that occur between stimulus and response cannot be observed and cannot be measured (Sarah, 2006). It can be observed is stimulus and response. 
Therefore, it is something given by the teacher (stimulus) and something that is accepted by the students (response) should be observed and measured (Fauziati, 2016). It focuses on the theory of measurement, since the measurement is an important thing to notice changes in behavior occurs or not.

\section{Pavlov's Theory of Classical Conditioning}

Ivan Petrovich Pavlov was born 14 September 1849 in Ryazan; Russia is the village where his father Peter Dmitrievich Pavlov became a pastor. He was educated at church schools and went to Theological Seminary. Pavlov graduated as a medical scholar with a base area of physiology. In 1884 he became director of the department of physiology at the Institute of Experimental Medicine and initiate research on the physiology of digestion. Ivan Pavlov won the Nobel Prize in Physiology or Medicine field in 1904. Greatly, it influenced his work on conditioning Psychology behaviorism in America. His writing is a Work of the Digestive Glands (1902) and Conditioned Reflexes (1927).

Classic conditioning (conditioning or classical terms) is a process that Pavlov discovered through experiments on dogs, in which the original stimulus and paired with a neutral conditional stimulus repeatedly giving rise to the desired reaction. The experiments were performed Pavlov and other experts seem to be very affected by the views of behaviorism, in which the symptoms of a person's psychological views of his behavior. To understand the theory of classical conditioning as a wholeneed to understand there are two types of stimulus and two response types.

The two types of stimulus is the unconditioned stimulus (unconditioned stimulus - UCS), which automatically generates a stimulus that preceded the response without any learning examples: food and unconditioned stimulus (conditioned stimulus - CS), which previously neutral stimulus, eventually bringing a conditioned response after associated with the unconditioned stimulus (for example: food comes before the bell sounds). 
Based on the assumption that by using certain stimuli, human behavior can be changed according to what is desired. Then Pavlov conducted experiments using animal (dog) because he thinks animals have in common with humans. Nevertheless, with all its advantages, is fundamentally different from human beings to animals. He was experimenting with how to conduct surgery on a dog's cheek. The saliva gland is visible from outside. When shown something of food, it will come out the dog saliva. Now, before the food is shown, the red light is shown first, and food. Saliva water itself will come out anyway. If such action is done repeatedly, then at one time by just showing a red light without food then saliva water will come out anyway. The food is reasonable stimulus, while the red light is artificial stimuli. It turns out that such an act is done repeatedly; it will give rise to artificial stimulation condition for the onset of salivation in the dogs. This event is called: Conditional or Conditioned reflex response.

\section{Watson's Conditioning Theory}

Watson is a purely behaviorist. Watson study about learning aligned with other sciences such as physics or biology are strongly oriented towards empirical experience alone, that is as far as can be observed and measured. According to Watson, learning is a process of interaction between stimulus and response (Johnson, 2001). In this case, the stimulus and response is established from the behaviors that can be observed and can be measured. Watson acknowledges the mental changes in a person throughout the learning process, and he considered such things as a factor that should not be taken into account. It is believed that by the process of conditioning we can build a set of stimulusresponse connections, and more complex behaviors are learned by building up a series of responses (Watson, 1913).

\section{Thorndike's Theory of Connectivism}

Thorndike's view on learning is that it is the process of forming associations or bonds or he called it "the connection of a certain act with a certain situation and resultant pleasure." Thorndike also classifies laws of learning as follows: 
a) Law of Readiness

It points out that organism will learn only when he is physically and mentally ready for it. An organism that is getting ready to obtain a change in behavior, the implementation of these behaviors will lead to satisfaction of the individual so that the association tends to be reinforced.

b) Law of Exercise

It suggests that drill and practice increase efficiency and durability of learning. Law principles of exercise is the connection between the condition (which is a stimulant) with the action will be stronger because of the exercises, but will be weakened if the connection between the two was not continued or discontinued so that the principle of this law shows that the main principle of learning is repetition. The more often repeated, the subject matter will be more controlled.

c) Law of Effect

The relationship tends to be reinforced if the stimulus response and tend to be weakened as a result pleasant if the result is not satisfactory. This law refers to the stronger or weaker connections as a result of actions. An act which tends to be maintained with due fun and other times will be repeated. Conversely, an act that followed unpleasant consequences tends to be stopped and will not be repeated.

\section{Skinner's Theory of Operant Conditioning}

Concepts put forward by Skinner about learning is able to outperform other concepts put forward by the previous figures. He was able to explain concepts in a simple to learn and can demonstrate his concept of a comprehensive study. According to Skinner, the relationship between stimulus and response that occurs through the interaction of the environment, which then would lead to changes in behavior; it is not as simple as described by previous leaders. Therefore, to understand a person's behavior is absolutely necessary to first understand the relationship between the stimulus to each other, and to understand the response may be raised and the consequences that may arise as a result of the response. 
Skinner also noted that, by using mental changes as a tool to explain the behavior will only add to the complexity of the problem.

Therefore, any tool that is used needs further explanation, and so on. Of all the supporters of behaviorism Theory, Skinner'sTheory is the most influence. Learning programs such as the teaching machine, learning program, modules, and other learning programs are based on the concept of stimulus-response relationships and the importance reinforcing factors, an instructional program that implements learning theory proposed by Skinner.

According to Skinner, to reinforce the behavior or the behavior confirmed we need reinforcement. There are also types of reinforcement, positive reinforcement and negative reinforcement. Positive reinforcement is based on the principle that the frequency of a response increases because it was followed by a stimulus that contains award. Thus, the behavior of which is expected to increase due to be followed by a pleasant stimulus. Example, learners are always so studious to rank the bikes will be rewarded by their parents. Behavior to be repeated or improved is to study hard to become rank one and positive reinforcement / unpleasant stimulus is giving the bike.

Negative reinforcement is based on the principle that the frequency of a response increases because followed by a stimulus that is not fun to be removed. Thus, the behavior of which is expected to increase due to be followed by the removal of an unpleasant stimulus. Example, learners and teachers often ask eliminating / no questions do not criticize the teacher is pleased hearts so that learners will often ask. Thus, the behavior that you want to repeat or enhanced often asked and unpleasant stimulus you need to lose is criticism of teachers so that students are not shy and will often ask questions because the teacher does not criticize the unqualified / deviated (Baum, 2005; Chiesa, 1994; Pierce \& Cheney, 2013; Rachlin, 1991).

\section{Behaviorism and Foreign Language Teaching Methodology}

Behaviorism theory is crucial in foreign language learning. The influence of this theory can be seen in the implementation of teaching learning process using Grammar Translation Method 
(GTM), Direct Method (DM), Situational Language Teaching (SLT) and closely related to a particular language teaching method called Audiolingual Method (ALM). This ALM has two principles: (1) Stimulus-Response concept, and (2) an assumption that second language learning should reflect and imitate the perceived process of mother tongue learning.

According to Fauziati (2016) the application of behaviorism theory in Audiolingual method is as follows: (1) the organism is the learner, (2) the behavior as verbal behavior, (3) the stimulus as what is presented of the foreign language, (4) the response as the learners' reaction to the stimulus, and (5) the reinforcement as the extrinsic approval and praise of the teacher, fellow students, and self-satisfaction of target language use.

Based on the relation between behaviorism theory and ALM, it is clear now that ALM is marked by the following characteristics: (1) new language should always be dealt within the sequence of listening, speaking, reading, and writing with emphasis on teaching receptive skills before productive skills, as what is claimed by Alexander (1986, as cited in Johnson, 2001) stating that nothing will be spoken before it has been heard, and nothing will be written before it has been read, (2) habit formation through frequent repetition, (3) errors are avoided, (4) the use of dialogues as the chief means of presenting language, (5) using mimicry, memorization, and pattern drills techniques, (6) discouraging the use of mother tongue in the classroom, and (7) the use of language lab in conducting teaching and learning process.

With regard to pattern drills technique in behaviorism theory, Brooks as cited in Fauziati (2014) mentioned various types of pattern drills as follows:

1. Repetition: repeating utterances aloud as soon as they were sounded

2. Inflection: replacing one word in an utterance

3. Replacement: replacing one word in an utterance

4. Restatement: delivering utterances to students, and asking students to address it to someone else

5. Completion: repeating utterances in complete form

6. Transposition: changing word order when a word is added

7. Expansion: adding a word in a certain place of the utterance

8. Contraction: changing the phrase or clause with a single word 
9. Transformation: transforming a sentence into negative of interrogative, or through changes in tense, mood, voice, or modality

10. Integration: integrating two utterances

11. Rejoinder: making appropriate response to the given utterance

12. Restoration: asking students to restore a sequence of words taken from a sentence to its original form.

In accordance with the foreign teaching methodology, behaviorism gives several implications in languagelearning process. Those are as follows:

1. Shaping

Teachers usually teach simple behavior in the school, they do not teach complex behavior in teaching learning process. The complex behavior can be taught through shaping or successive approximations. Shaping refers to procedure in which successive approximation to some terminal behavior is reinforced. This process begins with the purposes of study, assignment analysis, students' activities and response to the reinforcement. (Blankship, 1981). Blankship (1981) states five steps of students' behavior in learning process:

a. Come on timein the class

b. Active in learningprocess

c. Show thegood resultof thetest

d. Doing their homework

2. Modelling

Modelling is one of types of learning on behaviorism. The language teacher often uses this method in language learning process. A learner imitates the teacher's behavior in learning process, ex: an English teacher reads English book regularly in the class in language learning process. Teacher is model for students in learning process then; the students will imitate the behavior. The students will also read regularly in the class like their teacher. 
3. Rewarding and punishing In the learning process a teacher often gives a punishment to their students because of students guiltiest. This punishment should be applied in wise ways in the class. The students often get reward when they get good achievements in learning process. This method is based on Skinner theory of reward and punishment. In teaching learning process students usually get a difficult with foreign language subject, so, they often get punishment from their teacher. Reward and punishment are one of the implications of Skinner behaviorism theories in teaching learning process especially in language learning.

4. Programmed learning

Programmed learning is the application of the principles of operant conditioning. This learning process happens when the students get assignment from the teacher and they do it. In language learning process the teacher gives assignment to the students to read the story in their foreign language book they will do it.

Programmed learning has four purposes such as:

a. Summarizing the learning material

b. Forcing the students read the learning materials

c. Giving the result of learning directly to the teacher

d. Using effective time in learning

5. Assigning

There are several task components of learning in behaviorism, those are:

a. Purposes and study in behavioral

b. Divides task into sub task

c. Determine the relation between sub task

d. Determine material and procedures of sub task

e. Giving feedback in the end of sub task.

These learning component means the students always do the task and divide it into sub task. In language learning process the students always practice the task from language teacher, then, the result will be analyzed by the teacher. 
The last implication of behaviorism of language and learning in language learning is language acquisition theories. The behaviorist has found the language acquisition theories and these theories has been applied until today. Behaviorist says that human born without any perception of language or it is called tabula rasa and human learns language from their environments.

The language is form of culture and human uses the language as means of communicating. It means that human communicates with their own language. The behaviorism theory of learning gives good implication in teaching learning especially in language learning process. According to Thorndike there are two implications of behaviorism in language learning. Those are Theoretical and Practical.

In theoretical implication, the implication of behaviorism is based on the theory of learning in behaviorism. Thorndike stated that the four laws of learning gives good contribution inlanguagelearning. In practical implication, Thorndike stressed the importance of habits and procedures in learning especially in language learning process (Barash, 2005).

According to Skinner, the theoretical implications of operant theory creating an effective behavioral language, vocabulary and grammar such a language must allow behavioral phenomena to be coherently described. Among the useful aspect of the contemporary language of operant theory are the distinction between omission and elicitation of responses, the extension of this vocabulary discrimination the usage of response.

A behavioral language may be particularly effective in extensions to verbal behavior. Speaking and writing are kinds of behavior, but vocabulary creates difficulties for a behavioral account. For example, human speak using words. This vocabulary not only fails to distinguish spoken to written verbal behavior but also treats words as things rather than as kinds of responses. Verbal behavior has often been treated as if skinner derived all language from the stimulus-response associations of other varieties of behaviorism. (Gazda\& Raymond, 1980).

\section{Behaviorism Theory and Teaching Writing as Product}

As clearly stated before that the classroom practices in behaviorism theory is characterized by mimicry and the avoidance of error, it has a close connection to an approach of 
teaching writing called product approach (Staats\&Staats, 1963; Staddon, 2014). Mimicry itself is an activity of imitating behavior or speech. In teaching writing as product, the main procedures involve imitating and transforming models provided by the teacher, and emphasizing the error free final product. In the product approach, the classroom activities concern with the final product of writing and what the product should look like the model given (Fauziati, 2014). Therefore, we can say that behaviorism theory underlies the product approach in teaching writing.

\section{CONCLUSION}

In Behavioral theory, human behavior is the result of learning, so it can be changed by manipulating and creating learning conditions. Behaviorism theory strongly emphasizes the behavior or behavior that can be observed. Theories in the very nature of molecular clumps, because looking at the lives of individuals composed of elements like molecules. Characteristic of this theory is prioritizing the elements and a small part, is mechanistic, emphasizing the role of the environment, concerned with the formation of a reaction or response, emphasizing the importance of exercise, concerned with the mechanism of learning outcomes, concerned with the role of ability and learning results obtained is the emergence of the desired behavior. On learning theory is often called psychological SR means that human behavior is controlled by rewards or reward and reinforcement or reinforcement from the environment. Thus, the learning behavior is closely interwoven between behavioral reactions to stimulus. Teachers who hold this view say that student behavior is a reaction to the environment and the behavior is the result of learning.

\section{SHORT BIOGRAPHY}

Asep Budiman is a graduate student in English Education Department at SebelasMaret University of Surakarta, Central Java, Indonesia. He received his Bachelor Degree from the same department in Muhammadiyah University of Purwokerto, Indonesia. He has experience in teaching English in some schools, English courses and English Debate forums. His research interest includes motivation in EFL, language testing, and TEFL. 


\section{REFERENCES}

Alissa, D., E. (2003). Behaviorism: More than a Failure to Follow in Darwin's Footsteps. Illinois: Jossey-Bass.American History Vol (87) (2), pp. 686.

Barash, D., P. (2005). B.F. Skinner, Revisited. The Chronicle of Higher Education. Washington: Vintage Books.

Baum, W.M. (2005) Understanding behaviorism: Behavior, Culture and Evolution. New York: Blackwell.

Chiesa, M. (1994). A History of Behavioral Psychology. New York: New York University Press.

Fauziati, E. (2014). Methods of Teaching English as a Foreign Language (TEFL): Traditional Method, Designer Method, Communicative Approach, Scientific Approach. Surakarta: Era Pustaka Utama.

Fauziati, E. (2016). Applied Linguistics: Principles of Foreign Language Teaching, Learning, and Researching. Surakarta: Era Pustaka Utama.

Gazda,M. G., \&Raymond, J. (1980). TheoriesofLearninga Comparative Approaches. Illinois: Peacock publisherInc.

Johnson, K. (2001). An Introduction to Foreign Language Learning and Teaching. Harlow: Pearson Education Limited.

Leahey, T., H. (2000). A History of Behavioral Psychology. New York: Freeman.

Lodico, M. G., Spaulding, D. T., Voegtle. K. H. (2006). Methods in Educational Research: $\quad$ From Theory to Practice. San Francisco: Jossey-Bass.

Pierce, W., \& Cheney, C., D. (2013). Behavior Analysis and Learning, (5 ${ }^{\text {th }}$ Edition). New York: Psychology Press.

Rachlin, H. (1991). Introduction to modern behaviorism, (3rd edition) New York: Freeman.

Sarah E. I. (2006). Bending Behavior. American Scientist. Research Triangle Park. Vol (94) (3), pp. 267.

Skinner, B. F. (1976). About Behaviorism. New York: Vintage Books.

Staats, W., \&Staats, K. (1963). Complex human behavior: A systematic extension of learning principles. New York: Holt, Rinehart \& Winston. 
Staddon, J. (2014) The New Behaviorism, (2 ${ }^{\text {nd }}$ Edition). Philadelphia: Psychology Press.

Watson, J.B. (1913). "Psychology as the Behaviorist Views It". Psychological Review, 20: 158-177. 